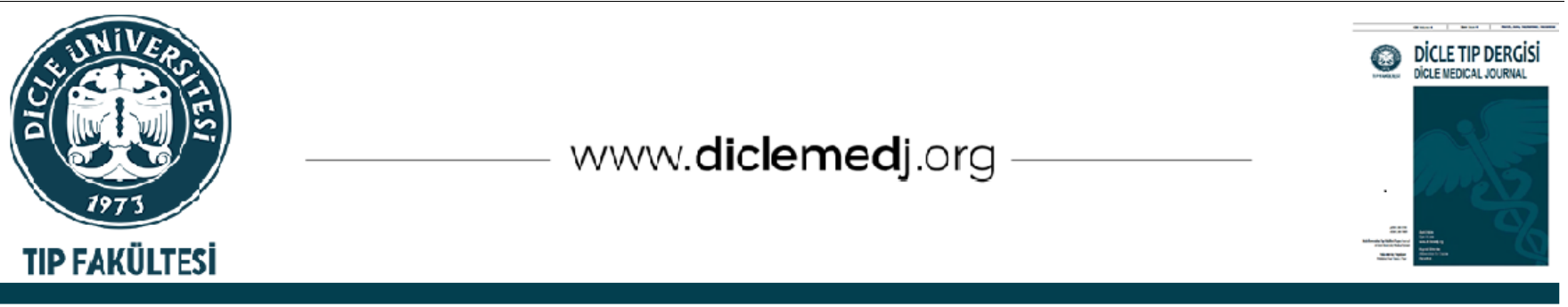

Özgün Araştırma / Original Article

\title{
Kistik fibrozis tanılı çocuk hastaların kardiyak değerlendirilmesi
}

\author{
Mehmet Türe ${ }^{D_{1}}$, Velat Şen ${ }^{D_{2}}$ \\ 1 Dicle Üniversitesi Hastanesi, Çocuk Kardiyoloji Bilim Dalı, Diyarbakır, Türkiye \\ 2 Dicle Üniversitesi Hastanesi, Çocuk Göğüs Hastalıkları Bilim Dalı, Diyarbakır, Türkiye
}

Geliş: 21.04.2021; Revizyon: 28.06.2021; Kabul Tarihi: 25.07.2021

\section{Öz}

Amaç: Kistik fibrozis: kalbi de etkileyen ilerleyici organ disfonksiyonu ile karakterize, kompleks, multisistemik kronik bir hastalıktır. Kistik fibrozis hastalarında gelişen kronik hipoksi, hiperkapni, sağ kalp boşluklarının dilatasyonu ve kullanılan sempatomimetik ilaçlar aritmiye neden olabilir. Çalışmamızın amacı kistik fibrozis tanılı çocuk hastaların elektrokardiyografi ve ekokardiyografi verilerini sağlıklı kontrol grubu ile karşılaştırarak ani ölüm açısından öngörüde bulunmak ve hastaların takiplerinde buna dikkat çekmektir.

Yöntemler: Elli bir kistik fibrozis tanılı çocuk hasta ile yaş ve cinsiyeti hasta grubu ile uyumlu olan 53 sağlıklı çocuk elektrokardiyografi verileri, sağ ventrikül sistolik basıncı ve sağ ventrikül sistolik fonksiyonlarını gösteren triküspit anüler düzlem sistolik hareketi açısından karşılaştırıldı.

Bulgular: Kistik fibrozis tanılı hastalarımızın 22'si (\%43,1) kız iken, yaş ortalaması 107,9 $\pm 59,7$ ay idi. Kotrol grubunun ise 25 'i kız $(\% 47,1)$ iken, yaş ortalaması 108,1 $\pm 59,7$ ay idi. Kontrol grubu ile karşılaștırıldığında, hasta grubunda kalp hızı ( $p=0.03), Q T$ dispersiyonu ( $p=0.002)$, QTc maksimum ( $p=0.01)$, QTc dispersiyonu $(p=0.002)$ anlaml olarak daha yüksekti. Triküspit anüler düzlem sistolik hareketi hasta grubunda kontrol grubuna göre $(p<0,001)$ anlamlı olarak düşük saptandi.

Sonuç: Kistik fibrozis tanılı çocuk hastalarda, pulmoner kan basıncındaki artış kalp yetmezliğinin erken belirtisi olabilir. Bu tür kardiyak bozuklukların, akciğer fonksiyonunun kronik inflamasyonuna bağlı kademeli olarak ortaya çıkabileceğini ve bu nedenle hastaları klinik olarak stabil tutmak ve kistik fibrozisin ilerlemesinde kronik inflamasyonu mümkün olduğunca erken kontrol altına almak çok önemlidir. Kistik fibrozis tanılı hastalarımızın kontrol grubuna göre aritmiye sebep olabilecek elektrokardiyografi değişiklikleri ve sağ ventrikül sistolik fonksiyonunu yansitan triküspit anüler düzlem sistolik hareketi düşük olduğu için sağ kalp yetmezliği, aritmi ve ani ölüm açısından yakından takip edilmeleri gerektiğini düşünüyoruz.

Anahtar kelimeler: Kistik fibrozis, çocuk, elektrokardiyografi, ekokardiyografi, aritmi

DOI: $10.5798 /$ dicletip.988071

Correspondence / Yazışma Adresi: Mehmet Türe, Dicle Üniversitesi Hastanesi, Çocuk Kardiyoloji Bilim Dalı, Diyarbakır, Türkiye email:drture21@gmail.com 


\section{Cardiac evaluation of pediatric patients diagnosed with cystic fibrosis}

\section{Abstract}

Objective: Chronic hypoxia, hypercapnia, dilatation of the right heart chambers and sympathomimetic drugs used in patients with cystic fibrosis may cause arrhythmia. The aim of our study is to predict sudden death by comparing the electrocardiography and echocardiography data of pediatric patients with cystic fibrosis with the healthy control group and to draw attention to this in the follow-up of the patients.

Methods: Fifty-one pediatric patients with a diagnosis of cystic fibrosis and 53 healthy children whose age and gender were compatible with the patient group were compared in terms of electrocardiographic data, right ventricular systolic pressure and tricuspid annular plane systolic movement showing right ventricular systolic functions.

Results: While 22 (43.1\%) of our cystic fibrosis patients were girls, the mean age was $107.9 \pm 59.7$ months. While 25 of the control group were girls (47.1\%), the mean age was $108.1 \pm 59.7$ months. Heart rate $(p=0.03)$, QT dispersion $(p=$ 0.002), QTc maximum ( $p=0.01)$, and QTc dispersion ( $p=0.002$ ) were significantly higher in the patient group compared to the control group. Tricuspid annular plane systolic movement was found to be significantly lower in the patient group compared to the control group $(\mathrm{p}<0.001)$.

Conclusions: We think that our patients with a diagnosis of cystic fibrosis should be closely monitored in terms of right heart failure, arrhythmia and sudden death, since electrocardiographic changes that may cause arrhythmia and tricuspid annular plane systolic movement reflecting right ventricular systolic function are low compared to the control group.

Keywords: Cystic fibrosis, child, electrocardiography, echocardiography, arrhythmia.

\section{GíRiş}

Kistik fibrozis (KF); Beyaz ırkta en yaygın ölümcül genetik hastalıktır. Kistik fibrozis; akciğer, gastrointestinal sistem, genitoüriner sistem ve ekzokrin bezlerin etkilendiği multisistemik bir hastalıktır. Akciğer tutulumu mortalite ve morbiditeden sorumludur ${ }^{1}$. Kistik fibroziste kronik enfeksiyon ve inflamasyona bağlı olarak akciğer yapısında ve fonksiyonunda ilerleyici kötüleşme, morbidite ve mortalite oranlarının artmasına neden olur. Diğer kronik akciğer hastalıklarında olduğu gibi, KF'de de kardiyak tutulum, akciğer hastalığının ilerlemesi ve hipoksinin varlığı ile ilişkilendirilmiştir. Kistik fibrozis hastalarında kronik akciğer hastalığına bağlı kor pulmonale gelișebilir. Kor pulmonale: kistik fibrozisin en ciddi kardiyovasküler komplikasyonudur ${ }^{2}$. Sağ ventrikül (RV) yetmezliğinin hastalığın şiddetine paralel olarak ilerlediği ve akciğer yıkımından kaynaklanan kronik hipoksiye bağlı olarak artan pulmoner arter basıncına ikincil olduğu düşünülmektedir. Sağ ventrikül genişlemesi ve disfonksiyonu olarak tanımlanan kor pulmonale, ilerleyerek sağ kalp yetmezliğine ilerleyebilmektedir ${ }^{3}$. Süt çocukluğu döneminde kor pulmonalenin insidansı ve prognozu tam olarak bilinmemektedir, ancak klinik, ekokardiyografik ve otopsi çalışmaları KF'li hastalarda yüksek bir RV hipertrofisi ve dilatasyonu prevalansı bulmuşlardır. Kor pulmonaleye sekonder RV yetmezliğinin ortaya çıkması kötü prognozun işaretidir ${ }^{3}$.

Kronik pulmoner enfeksiyonlar ve persistan sistemik inflamasyonun kardiak fonksiyonlar üzerinde ciddi etkileri olabilir. İnflamatuar mediatörlerin miyokardial fonksiyonları deprese ettiğine dair deneysel çalışmalar mevcuttur ${ }^{4}$. Kistik fibrozis hastalarında ritm problemleriyle ilgili yeterli çalışma bulunmamakla beraber aritmilerin saptandığ vaka sunumları vardır ${ }^{5}$. Kistik fibrozisli hastalarda kullanılan sempatomimetik ilaçlar, hipoksi, hiperkapni, asidoz, otonom disfonksiyon ve son dönemde gelişebilen kor pulmonale aritmi nedeni olabilir6,7.

Kistik fibrozis hastalarında hem sağ hem de sol ventrikül anormalliklerine bağlı kardiak 
disfonksiyon olduğu gösterilmiştir. Son zamanlardaki çalışmalarda kistik fibrozisin erken evrelerinde subklinik kardiak disfonksiyon saptanmıştır ${ }^{8,9}$. Bundan dolayı hastaların hayat kalitesinin arttırılması ve kistik fibrozise bağlı komorbiditeleri azaltmak için rutin kardiak fonksiyon takibi önerilmektedir. Ekokardiyografi (EKO) ve elektrokardiyografi (EKG); ucuz, hızlı tanı imkanı tanıdığı için takipte kullanılmaktadır. Kardiak disfonksiyonun; kistik fibrozisli hastalarda en önemli ekstra-pulmoner komplikasyonlardan bir tanesi olması ve erken dönemde tedavisinin hastanın hayatta kalım ve hayat kalitesini arttıracağı düşünülmektedir. $\mathrm{Bu}$ çalışmada kistik fibrozis hastalarının elektrokardiyografi ve ekokardiyografi bulgulariyla değerlendirilmesi ve sağlıklı çocuklarla karşılaştırılması amaçlanmıştır.

\section{YÖNTEMLER}

Çalışmamıza 1 Ocak 2020- 1 Ocak 2021 tarihleri arasında Dicle üniversitesi tıp fakültesi hastanesi çocuk göğüs hastalıkları tarafından takip edilen ve çocuk kardiyoloji polikliniğine rutin kardiak değerlendirme için gönderilen kistik fibrozis tanısı olan 51 çocuk hasta ve nonspesifik şikayetlerle polikliniklerimize başvurmuş, bilinen herhangi bir kronik hastalığı olmayan, hasta grubu ile benzer yaş ve cinsiyetteki 53 sağlıklı çocuk dahil edildi. Hastaların ve kontrol grubunun demografik özellikleri, 12 derivasyonlu EKG kayıtları, EKO kayıtları incelendi. Bilinen başka kronik hastalığı olanlar, doğuştan kalp hastalığı olanlar, kalp fonksiyonlarını ve kardiyak ritmi etkileyebilecek ilaç kullanım öyküsü olanlar (kistik fibrozis tedavisi için kullanılan ilaçlar dışındaki ilaçlar) çalışma dışı bırakıldı. Katılan tüm olgular ve/veya aileleri çalışma hakkında bilgilendirildi ve kabul ettiklerine dair imzalı onamları alındı. Çalışma Dicle Üniversitesi Tıp Fakültesi Etik Kurulundan onay alınarak yapıldı (Tarih: 25.03.2021 ve Karar No: 202).
Katılan tüm olgulardan en az 10 dakika istirahat sonrası, kağıt hızı saniyede $25 \mathrm{~mm}$ olacak şekilde 12 derivasyonlu EKG kaydı alındı. Tüm derivasyonlarda EKG parametreleri olarak istirhatte kalp hızı, QRS süresi, QTminimum (QTmin), QTmaksimum (QTmaks), QT dispersiyonu (QTd), QTc minimum (QTcmin), QTc maksimum (QTcmaks), QTc dispersiyonu (QTdc), Tp-e maksimum (Tp-emaks), Tp-e maksimum/QT maksimum (Tpemaks/QTmaks), Tp-e maksimum/ QTc maksimum (Tp-emaks/QTcmaks) oranları ölçüldü ve ortalama değerler hesaplandı. QT aralığı, Q dalgasının başlangıcından T dalgasının sonuna kadar olan mesafe olarak tanımlandı. U dalgaları varsa QT aralığ arasındaki eğrinin en alt noktasında ölçüldü. RR aralığı ölçülmesi kalp hızını hesaplamak ve QT aralığını (QTc) Bazett formülü ile düzeltmek için kullanıldı. QTc ve düzeltilmiş QT dispersiyonu (QTdc), Bazett formülü (QTc=QT $/ \sqrt{R R})$ kullanılarak hesaplandı. QT dispersiyonu, farklı derivasyonlarda maksimum ve minimum QT aralığı arasındaki fark olarak belirlendi. Tp-e aralığı $\mathrm{T}$ dalgasının tepe noktasından $\mathrm{T}$ dalgasının sonuna kadar tanımlandı. Tp-e aralığı ölçümleri prekordiyal derivasyonlardan yapıldı. Tp-e/QTmaks ve Tp-e/QTcmaks oranları da hesapland. Hasta ve kontrol grubunun ekokardiyografilerinde ise sağ ventrikül sistolik basıncl (RVSP) ve sağ ventrikül sistolik fonksiyonlarını gösteren triküspit anüler düzlem sistolik hareketi (TAPSE), sol ventrikül ejeksiyon fraksiyonu (SVEF), sol ventrikül kısalma fraksiyonu (SVKF), sol ventrikül diastol sonu çapı (SVDSÇ), sol ventrikül sistol sonu çapı (SVSSÇ) bakıldı.

\section{İstatistiksel incelemeler}

Çalışmaya alınan vakalardan elde edilen veriler değerlendirilirken istatistiksel analizler için 'Statistical Package for Social Sciences (SPSS) for Windows v25.0.0' programı kullanıldı. 
Sayısal değişkenler ortalama, \pm standart sapma (sd), kategorik değişkenler sayı ve yüzde ile sunuldu. Verilerin normal dağılımını tespit etmek üzere shapiro wilk-w ve Kolmogorov Smirnov testi kullanıldı. Elde edilen veriler değerlendirilirken Chi-square, Student-t, MannWhitney U, testleri kullanıldı. Tüm testlerde $\mathrm{p}<$ 0,05 değerleri istatistiksel olarak anlamlı kabul edildi.

\section{BULGULAR}

Çalışmamıza kistik fibrozis tanılı 51 hasta ile yaş ve cinsiyeti hasta grubu ile uyumlu olan 53 kontrol grubu alındı. Kistik fibrozis hastalarımızın 22'si $(\% 43,1) \mathrm{kız}$ iken, yaş ortalaması $107,9 \pm 59,7$ ay idi. Kotrol grubunun ise $25^{\prime} \mathrm{i} \mathrm{klz}(\% 47,1)$ iken, yaş ortalamaları $108,1 \pm 59,7$ ay idi. Ortalama yaş, boy, kilo ve cinsiyet açısından hasta ve kontrol grubu arasında anlamlı farklılık saptanmadı (Tablo I).

Tablo I: Kistik fibrozis ve kontrol grubunun demografik verilerinin karşılaştırılması

\begin{tabular}{|l|l|l|l|}
\hline $\begin{array}{l}\text { Demografik } \\
\text { veriler }\end{array}$ & KF (n: 51) & $\begin{array}{l}\text { Kontrol (n: } \\
\mathbf{5 3})\end{array}$ & p değeri \\
\hline $\begin{array}{l}\text { Cinsiyet } \\
\text { (Kız/Erkek) }\end{array}$ & $22 / 29$ & $25 / 28$ & $\mathbf{0 . 6 8}$ \\
\hline Yaş (Ay) & $107.9 \pm 59.7$ & $108,1 \pm 51$ & $\mathbf{0 . 9 8}$ \\
\hline $\begin{array}{l}\text { Boy } \\
\text { (Santimetre) }\end{array}$ & $124.2 \pm 25.6$ & $131.8 \pm 20.5$ & $\mathbf{0 . 9 7}$ \\
\hline Kilo (Kilogram) & $27.7 \pm 16.2$ & $31.5 \pm 14.2$ & $\mathbf{0 . 2}$ \\
\hline
\end{tabular}

Ortalama \pm standart sapma, $n$ : Sayl, KF: Kistik fibrozi

Hasta grubu kontrol grubu ile karşılaştırıldığında hasta grubunda kalp hızı $(\mathrm{p}=0.03)$, QT dispersiyonu $(\mathrm{p}=0.002)$, QTc maksimum $(p=0.01), \quad$ QTc dispersiyonu $(\mathrm{p}=0.002)$ anlamlı olarak daha yüksekti (Tablo II).
Tablo II: Kistik fibrozis ve kontrol grubunun elektrokardiyografi (EKG) verilerinin karşılaştırılması

\begin{tabular}{|l|l|l|l|}
\hline EKG verileri & KF (n: 51) & $\begin{array}{l}\text { Kontrol } \\
\text { (n:53) }\end{array}$ & $\begin{array}{l}\text { p } \\
\text { değeri }\end{array}$ \\
\hline Kalp Hızı & $103.3 \pm 25.4$ & $94.4 \pm 15.8$ & $0.03^{*}$ \\
\hline QRS (s) & $0.076 \pm 0.009$ & $0.073 \pm 0.008$ & 0.247 \\
\hline QTmin (s) & $0.296 \pm 0.033$ & $0.303 \pm 0.024$ & 0.21 \\
\hline QTmaks (s) & $0.318 \pm 0.033$ & $0.316 \pm 0.022$ & 0.74 \\
\hline QTd (s) & $0.026 \pm 0.026$ & $0.013 \pm 0.007$ & $0.002^{*}$ \\
\hline QTcmin(s) & $0.384 \pm 0.024$ & $0.383 \pm 0.023$ & 0.819 \\
\hline QTcmaks (s) & $0.414 \pm 0.026$ & $0.402 \pm 0.021$ & $0.01^{*}$ \\
\hline QTdc(s) & $0.030 \pm 0.014$ & $0.019 \pm 0.010$ & $0.002^{*}$ \\
\hline Tp-emaks (s) & $0.072 \pm 0.009$ & $0.068 \pm 0.010$ & 0.10 \\
\hline $\begin{array}{l}\text { Tp- } \\
\text { emaks/QTmaks }\end{array}$ & $0.228 \pm 0.036$ & $0.227 \pm 0.030$ & 0.33 \\
\hline $\begin{array}{l}\text { Tp- } \\
\text { emaks/QTcmaks }\end{array}$ & $0.176 \pm 0.025$ & $0.175 \pm 0.022$ & 0.86 \\
\hline
\end{tabular}

*Istatistiksel olarak anlamlı Ortalama \pm standart sapma, $n$ : Sayl, s: saniye KF: Kistik fibrozis, QRS: QRS süresi, QTmin: QTminimum, QTmaks: QTmaksimum, QTd: QTdispersionu, QTcmin: QTc minimum, QTcmaks: QTcmaksimum, QTdc: QTc dispersionu, Tp-emaks: Tp-e maksimum, Tpemaks/QTmaks: Tp-emaksimum/QTmaksimum. Tp-emaks/QTcmaks: Tpemaksimum/QTcmaksimum.

İki grubun EKO bulgularından RVSP, SVEF, SVKF, SVDSÇ, SVSSÇ ölçümleri karşılaştırıldı ve istatistiksel olarak anlamlı fark saptanmadı. Triküspit anüler düzlem sistolik hareketi hasta grubunda kontrol grubuna göre $(\mathrm{p}<0,001)$ anlamlı olarak düşük saptandı (Tablo III).

Tablo III: Kistik fibrozis ve kontrol grubunun ekokardiyografi (EKO) verilerinin karşılaştırılması

\begin{tabular}{|l|l|l|l|}
\hline EKO verileri & $\begin{array}{l}\text { Kontrol } \\
(\mathbf{n}: 51)\end{array}$ & $\begin{array}{l}\text { Kontrol } \\
(\mathbf{n}: 53)\end{array}$ & p değeri \\
\hline SVEF $(\mathbf{m m})$ & $70.8 \pm 3.72$ & $70,6 \pm 4.09$ & $p>0,05$ \\
\hline SVKF $(\mathbf{m m})$ & $35.6 \pm 3.63$ & $35.7 \pm 2.26$ & $p>0,05$ \\
\hline SVDSÇ (mm) & $33.96 \pm 7.25$ & $35.5 \pm 5.54$ & $p>0,05$ \\
\hline SVSSÇ $(\mathbf{m m})$ & $21.33 \pm 5.38$ & $22.6 \pm 3.4$ & $p>0,05$ \\
\hline RVSP(mmHg & $25.3 \pm 4.38$ & $24.7 \pm 3.36$ & $p>0,05$ \\
\hline TAPSE $(\mathbf{m m})$ & $25.6 \pm 6.5$ & $31.5 \pm 6.1$ & $p<0,001^{*}$ \\
\hline
\end{tabular}

*istatistiksel olarak anlamlı Ortalama \pm standart sapma, $n$ : Sayı, KF: Kistik fibrozis, SVEF: Sol ventrikül ejeksiyon fraksiyonu, SVKF: Sol ventrikül kısalma fraksiyonu, SVDSÇ: Sol ventrikül diastol sonu çapı, SVSSÇ:Sol ventrikül sistol sonu çapı, RVSP: Sağ ventrikül sistolik basıncl, TAPSE: Triküspit anüler düzlem sistolik hareketi 


\section{TARTIŞMA}

Kistik fibroz; hayatı tehdit eden otozomal resesif bir hastalıktır ${ }^{10}$. KF'de kor pulmonale en ciddi kardiyovasküler komplikasyondur ${ }^{2}$. Kistik fibrozis hastalarında alveolar hipoksinin gelişimi pulmoner vazokonstriksiyona yol açar. $\mathrm{Bu}$ olayların pulmoner arter basınc (PAB) ve sağ ventrikül fonksiyonu üzerinde güçlü bir etkisi vardır11-13. $\mathrm{Bu}$ nedenle, bu hasta popülasyonunda sağ ventrikül fonksiyonunun değerlendirilmesi son derece önemlidir. Kistik fibroz hastalarında EKG'de sağ ventrikül hipertrofisi, sağ atrial hipertrofi, sağ aks sapması gibi nonspesifik değişiklikler görülebilir. Kistik fibrozis hastalarında hiperinflasyon nedeni ile kalp ve gögüs duvarı arasındaki anormal ilişkiden dolayı RV hipertrofisi gözden kaçabilir ${ }^{14,15}$. Bu nedenle bu hastaların EKG'si dikkatli ve ayrıntılı şekilde değerlendirilmelidir. Çalışmamızda kistik fibrozis tanılı çocukların aynı yaştaki sağlıklı kontroller ile kardiyak açıdan karşılaştırarak özellikle sağ kalp yetmezliği ve aritmi riski açısından değerlendirilmesi amaçlanmıştır.

Kistik fibrozis hastalarında aritmi ile ilgili kısıtlı sayıda çalışma vardır. Yapılan bir çalışmada ventriküler taşikardili bir kistik fibrozis vakasında, toksik ve metabolik olayların miyokard fibrozu ve nekrozuna yol açarak ritm bozukluğuna neden olabileceği öne sürülmüştür ${ }^{4}$. Başka bir çalışmada ise dört supraventriküler taşikardi tanılı kistik fibrozis vakasının üçünde kor pulmonale saptanmıştır. $\mathrm{Bu}$ hastalardan birinde elektrofizyolojik çalıșma ile gizli aksesuvar yol tespit edilmiştir. Diğer hastalarda ise kullanılan ilaçlar, sağ ventrikül ve sağ atrium dilatasyonu, kronik hipoksi, otonom disfonksiyon, disritmiden sorumlu etkenler olarak öne sürülmüştür 5 . İstirahatte yüksek kalp hızı, uzamış QRS süresi ve uzamış QT intervali gibi EKG anormallikleri kardivasküler risk ile ilişkilidirr ${ }^{16}$. QT aralığl; ventriküler depolarizasyonun başlangıcından repolarizasyonun tamamlanmasina kadar geçen süreyi temsil eder. Yapılan bir çalışmada da düzeltilmiş QT aralığı ile kardiyovasküler ölüm arasında ilişki olduğu gösterilmiștir ${ }^{17}$. Maksimum ve minimum QT aralığı arasındaki fark olarak tanımlanan QTd ventriküler repolarizasyonun heterojenliğini temsil eder ve ventriküler aritmilerin bir prediktörü olarak rapor edilir ${ }^{18}$. Artmış QTd de ani kardiyak ölümle ilişkilendirilmiştir. Kistik fibrozis tanılı çocuklarda yapılan bir çalışmada kontrol grubuna göre QTd ve QTdc yüksek bulunmuş bundan dolayı ventriküler repolarizasyonun sağlıklı kontrollere göre daha heterojen olduğunu ve bunun artmış aritmi riskini gösterebileceği düşünülmüştür ${ }^{19}$.

Tp-e aralığı ventriküler repolarizasyonu gösteren EKG parametresidir. Normal QTc'li hastalarda bile ventriküler aritmiler ve ani ölüm ile ilişkilendirilmiştir. Tp-e / QT oranı da son dönemlerde repolarizasyon için yeni elektrokardiyografik marker olarak kullanılmıştır ve malign ventriküler aritmiler ile ilişkili olduğu bildirilmiştir ${ }^{20}$.

Elektrokardiyogramda $\mathrm{T}$ dalgasının tepe noktası ile sonu arasındaki aralık olarak hesaplanan repolarizasyonun transmural dispersiyonu, ventriküler aritmiler ve ani kalp ölümü ile ilişkilendirilmiştir ${ }^{21}$ Yapılan çalışmalar, Tp-e aralığı, Tp-e / QT oranı ve Tp-e / QTc oranının, repolarizasyonun dağılımının bir indeksi olarak kullanılabileceğini göstermiştir ${ }^{22}$. Ayrıca, bu belirteçler ventriküler aritmogenez ve ani kardiyak ölümün elektrokardiyografik indeksi olarak kullanılabilir ${ }^{21}$. Başka çalışmalar da Tp-e aralığı ve Tp-e/QT oranının artmış malign ventriküler aritmi riski ile ilişkili olduğunu göstermiştir ${ }^{21,23}$.

Literatür taramamızda KF hastalarında sadece bir çalışmada QT ve QTd bakılmış ve anlamlı şekilde yüksek saptanmış ${ }^{19}$ ancak KF hastalarında Tp-e aralığı, Tp-e / QT oranı ve Tpe / QTc oranının değerlendirildiği çalışmaya rastlamadık. 
Çalışmamızda

elektrokardiyografi

yapilan

ayrintılı değerlendirilmesinde kontrol grubuna göre kalp hızı, QTd, QTcmaks ve QTdc hasta grubunda daha yüksek saptandı. Diğer EKG parametrelerinin kontrol grubuna göre anlamlı şekilde yüksek olmamasını hastalarımızın çocuk yaşta olmasına bağladık. Kistik fibrozis hastalarımızın yetişkin döneme geldiklerinde sağ ventrikül fonksiyon bozukluğu ile beraber diğer EKG parametrelerinin de bozulacağını tahmin etmekteyiz. Ancak bunu desteklemek için uzun süre takip edilmesi gerektiğini düşünüyoruz.

Yapılan bir çalışmada şiddetli hastalığı olan erişkin KF hastalarının \%20-65'inde pulmoner hipertansiyon (PH) saptanmıștır ${ }^{24}$. Bununla birlikte, daha hafif hastalığı olan hastalar arasında sıklığ sınırlıdır. Bazı çalışmalar sağ ventrikül sistolik fonksiyonunun korunduğunu saptamıștır ${ }^{25}$. Sağ ventrikül disfonksiyonu derecesi, özellikle eşlik eden bir PH bulgusu mevcutsa, hastalığın ciddiyetine paralellik göstermektedir ${ }^{26}$. Sağ ventrikül sistolik fonksiyonunun değerlendirilmesinde hızlı ve invazif olmayan bir yöntem olduğu kanıtlanmış bir parametre olan TAPSE'nin ölçümü kullanılabilir. Çalışmamızda hastalarımız çocuk olmasına rağmen ve sağ ventrikül sistolik basıncı kontrol grubuna göre anlamlı şekilde yüksek olmamasına rağmen hastalarda kontrol grubuna göre TAPSE değerini istatistiksel olarak daha düşük saptadık. Bu da hastaların kontrol grubuna göre hayatlarının ilerleyen dönemlerinde sağ ventrikül sistolik disfonksiyonu için bir gösterge olabilir.

Kistik fibrozis hastalarında sağ ventriküle odaklanan çalışmaların aksine, primer sol ventrikül disfonksiyonuna dair kanıtlar azdır. Yapılan bir çalışmada hem çocuklarda hem de yetişkin KF hastalarında sol ventrikülün sistolik fonksiyonu normal saptanmıștır27. Çalışmamızda da KF hastalarımızda kontrol grubuna göre sol ventrikül sistolik fonksiyonu ve sol ventrikül çapları açısından anlamlı farklılık saptanmadı.

\section{SONUÇ}

Kistik fibrozisli hastalarda hipoksi, hiperkapni, elektrolit bozuklukları, kullanılan ilaçlar, otonom disfonksiyon anormal elektrokardiyografi değişikliklerine neden olabilir. Çalışmamızda kistik fibrozis hastalarının elektrokardiyografi verileri daha önce yapılmamış ş̧ekilde ayrıntılı şekilde değerlendirilmiştir. Ventriküler aritmilerin ön belirleyici parametrelerinden olan QTd, QTcmaks ve QTdc kistik fibrozis hastalarımızda kontrol grubuna göre anlamlı şekilde yüksek saptandı. Hastalarımızın sağ ventrikül sistolik basıncı normal saptanmasına rağmen să̆ ventrikül sistolik fonksiyonunu yansitan triküspit anüler düzlem sistolik hareketi kistik fibrozis hastalarında kontrol grubuna göre anlamlı olarak daha düşük saptandı. Hastalarımızın çocuk olmasına rağmen elektrokardiyografi ve TAPSE'deki anormallikler hastaların hayatlarının ilerleyen dönemlerinde sağ kalp yetmezliği ve aritmiler açısından risk altında olduklarını ve bu riskleri engellemek için hastaların kardiyak açıdan da düzenli ve yakın takip edilmesi gerektiğini göstermektedir.

\section{Çalışmanın kısıtlılıkları}

Çalışmanın tek merkezli olması ve hasta sayısının az olması çalışmamızın kısıtlılıkları arasındadır. Daha büyük bir hasta popülasyonu daha kesin sonuçlar ortaya çıaracaktır. Hastaların aritmi ve ani ölüm ile ilgili klinik takiplerinin olmaması da diğer önemli kısıtlllıktır. Sonuçların doğruluğunu arttırmak için daha fazla hasta ve daha uzun takip süresi ile daha fazla çalışma yapılması gerekmektedir.

Etik Kurul Kararı: Çalıșma Dicle Üniversitesi Tıp Fakültesi Etik Kurulundan onay alınarak yapıldı (Tarih: 25.03.2021 ve Karar No:202). 
Çıkar Çatışması Beyanı: Çıkar çatışması bulunmamaktadır.

Finansal Destek: Bu çalışma her hangi bir fon tarafından desteklenmemiștir.

Declaration of Conflicting Interests: The author declare that she has no conflict of interest.

Financial Disclosure: No financial support was received.

\section{KAYNAKLAR}

1. Moss AJ. The cardiovascular system in cystic fibrosis. Pediatrics 1982; 70: 728-41.

2. N. Ozcelik, R. Shell, M. Holtzlander, et al. Decreased right ventricular function in healthy pediatric cystic fibrosis patients versus non-cystic fibrosis patients Pediatr Cardiol. 2013; 34: 159-64.

3. RJ Bright-Thomas, AK Webb. Kistik fibrozda kalp JR Soc Med. 2002; 95: 2 - 10

4. Cheron G, Paradis K, Steru D, et al. Cardiac involvement in cystic fibrosis revealed by a ventricular arrhythmia. Acta Paediatr Scand 1984; 73: 697-700.

5. Sullivan MM, Moss RB, Hindi RD, et al. Supraventricular tachycardia in patients with cystic fibrosis. Chest 1986; 90: 239-42.

6. Shih HT, Webb CR, Conway WA, et al. Frequency and significance of cardiac arrhythmias in chronic obstructive lung disease. Chest 1988; 94: 44-8.

7. Pierson DJ, Hudson LD, Stark $K$, et al. Cardiopulmonary effects of terbutaline and a bronchodilator combination in chronic obstructive pulmonary disease. Chest 1980; 77: 176-82.

8. A. Baño-Rodrigo, A. Salcedo-Posadas, J.R. VillaAsensi, et al. Right ventricular dysfunction in adolescents with mild cystic fibrosis Journal of Cystic Fibrosis. 2012; 11: 274-80.

9. Z.M. Sellers, V. De Arcangelis, Y. Xiang, P.M. Best Cardiomyocytes with disrupted CFTR function require CaMKII and $\mathrm{Ca}(2+)$-activated $\mathrm{Cl}(-)$ channel activity to maintain contraction rate J Physiol. 2010; 588: 2417-29.
10. T.P. Abraham, V.L. Dimaano, H.Y. Liang. Role of tissue Doppler and strain echocardiography in current clinical practice Circulation. 2007; 116: 2597-609.

11. Fraser KL, Tullis DE, Sasso Z, et al. Pulmonary Hypertension and Cardiac Function in Adult Cystic Fibrosis. Role of Hypoxemia. Chest 1999; 115: 13218.

12. Lopez L, Colan SD, Frommelt PC, et al. Recommendations for quantification methods during the performance of a pediatric echocardiogram: a report from the Pediatric Measurements Writing Group of the American Society of Echocardiography Pediatric and Congenital Heart Disease Council. J Am Soc Echocardiogr 2010; 23: 465-95.

13. Lang RM, Bierig M, Devereux RB, et al. American Society of Echocardiography's Nomenclature and Standards Committee; Task Force on Chamber Quantification; American College of Cardiology Echocardiography Committee; American Heart Association; European Association of Echocardiography, European Society of Cardiology. Eur J Echocardiogr 2006; 7: 79-88.

14. Stern RC, Borkat G, Hirschfeld SS, et al. Heart failure in cystic fibrosis. Treatment and prognosis of cor pulmonale with failure of the right side of the heart. Am J Dis Child 1980; 134: 267-72.

15. May CD, U LC. Fibrosis of the pancreas in infants and children. An illustrated review of certain clinical features with special emphasis on the pulmonary and cardiac aspects. J Pediatr 1949; 34: 663.

16. O'Neil BJ, Hoekstra J, Pride YB, et al. Incremental benefit of 80-lead electrocardiogram body surface mapping over the 12-lead electrocardiogram in the detection of acute coronary syndromes in patients without ST-elevation myocardial infarction: Results from the Optimal Cardiovascular Diagnostic Evaluation Enabling Faster Treatment of Myocardial Infarction (OCCULT MI) trial. Acad Emerg Med. 2010; 17: 932-9.

17. Montanez A, Ruskin JN, Hebert PR, et al. Prolonged QTc interval and risks of total and cardiovascular mortality and sudden death in the general population: a review and qualitative 
overview of the prospective cohort studies. Arc Intern Med 2004; 164: 943-8.

18. Piccirillo G, Magri D, Matera S, et al. QT variability strongly predicts sudden cardiac death in asymptomatic subjects with mild or moderate left ventricular systolic dysfunction: a prospective study. Eur Heart J. 2007; 28: 1344-50.

19. Figen Akalın, Canan Ayabakan, Ömer Güran, et al. Kistik fibrozisli hastalarda QT dispersiyonu. Çocuk Sağlığı ve Hastalıkları Dergisi 2004; 47: 244-8.

20. Antzelevitch C, Oliva A. Amplification of spatial dispersion of repolarization underlies sudden cardiac death associated with catecholaminergic polymorphic VT, long QT, short QT and Brugada syndromes. J Intern Med. 2006; 259: 48-58.

21. Castro Hevia J, Antzelevitch C, Torne's Ba'rzaga $\mathrm{F}$, et al. Tpeak-Tend and Tpeak-Tend dispersion as risk factors for ventricular tachycardia/ventricular fibrillation in patients with the Brugada syndrome. J Am Coll Cardiol 2006; 47: 1828-34.

22. Kors JA, Ritsema van Eck HJ, van Herpen G. TpTe aralığının anlamı ve tanısal değeri. J Electrocardiol 2008; 41: 575-80.
23. Erikssen G, Liestøl K, Gullestad L, et al. The terminal part of the QT interval ( $\mathrm{T}$ peak to $\mathrm{T}$ end): $\mathrm{a}$ predictor of mortality after acute myocardial infarction. Ann Noninvasive Electrocardiol. 2012; 17: 85-94.

24. Manika K, Pitsiou GG, Boutou AK, et al. The Impact of Pulmonary Arterial Pressure on Exercise Capacity in Mild-to-Moderate Cystic Fibrosis:A Case Control Study. Pulmonary Medicine 2012; 6.

25. Burghuber OC, Salzer-Muhar U, Gotz M. Right ventricular contractility is preserved in patients with cystic fibrosis and pulmonary artery hypertension. Scand J Gastroenterol Suppl 1988; 143: 938.

26. Matthay RA, Berger HJ, Loke J, et al. Right and left ventricular performance in ambulatory young adults with cystic fibrosis. Br Heart J 1980; 43: 47480.

27. Sellers ZM, Kovacs A, Weinheimer CJ, et al. Left ventricular and aortic dysfunction in cystic fibrosis mice. Journal of Cystic Fibrosis 2013; 12: 517-24. 